\title{
Selecting Pigs for Youth Swine Shows
}

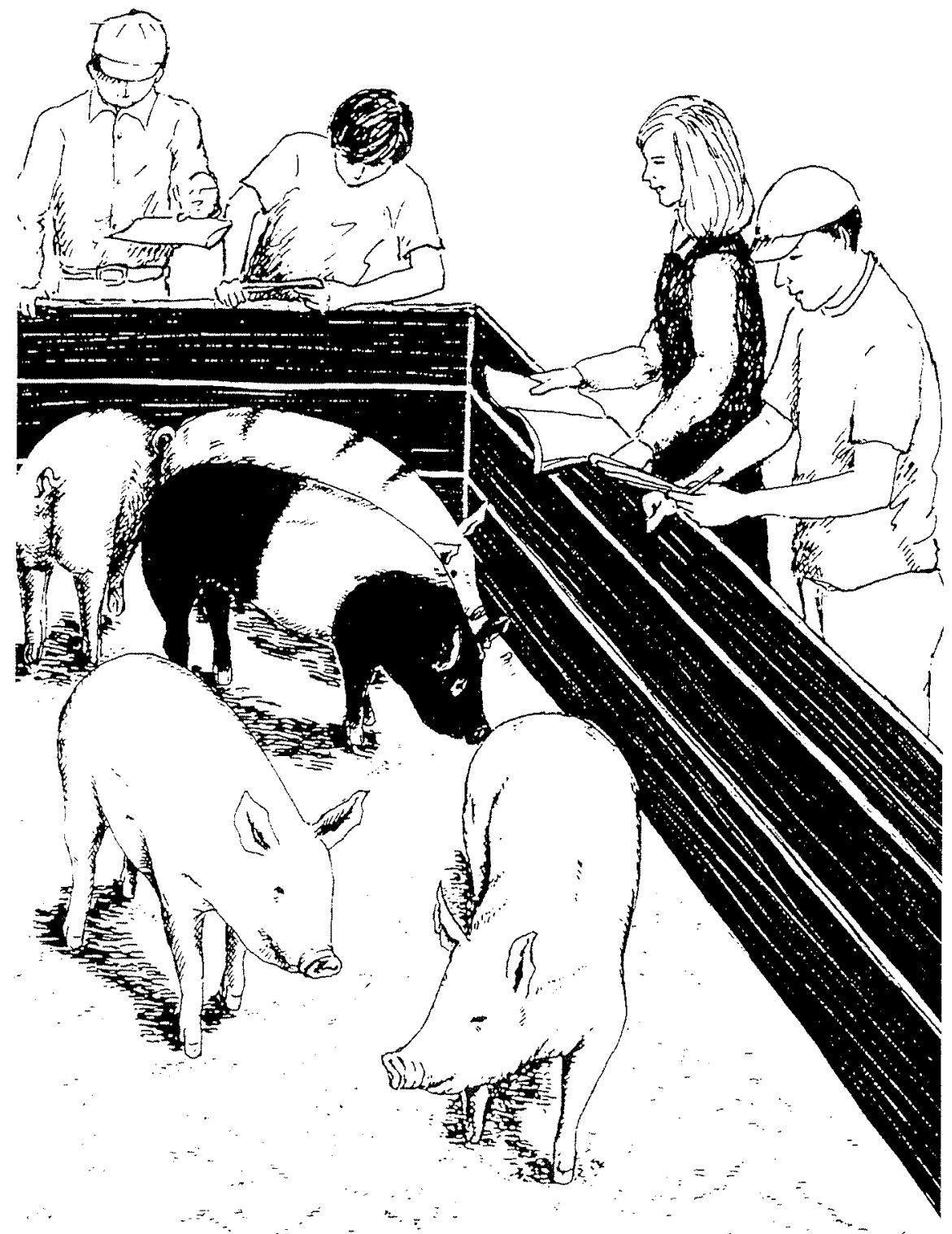

by

Timothy T. Marshall

William R. Walker

David L. Prichard

Saundra H. TenBroeck

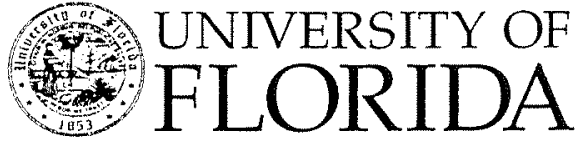

Institute of Food and Agricultural Sciences

Florida Cooperative Extension Service / Institute of Food and Agricultural Sciences University of Florida, Gainesville / Christine Taylor Waddill for Extension 


\section{Introduction}

This publication is intended to help youth exhibitors determine how and where to buy feeder pigs, and to provide a means of evaluating potential show pigs. Among the questions that this publication will help answer are:

1. Where should I buy a pig?

2. Should I contact a swine producer or work through my club or chapter to buy a group of pigs?

3. What breed or cross should I buy?

4. What should my pig look like on the day of the show?

5. How do I select a pig to fit the feeding period dictated by the show?

\section{Where Should I Buy My Pig?}

You can avoid many problems by obtaining pigs from an acceptable source. The most important consideration in choosing a source of pigs is good health. Make sure that the herd you pick from is on a good parasite control program and is free from all infective swine diseases. Do not buy pigs that are coughing, scratching, or look unthrifty. Ask the producer about his deworming program, external parasite control and vaccination schedule. If you are buying pigs from out of state, make sure that all necessary health papers are available before hauling. Even if the pig you want is thrifty, do not buy from a producer who has a number of sick pigs or you may bring home more than you bargained for.

When possible, know the history of the pig you select. Ask for performance records and carcass data from related pigs. Even the best feeding program cannot overcome poor genetic potential.

It is possible for a small hog producer to have the best pigs available. However, producers of large numbers of pigs can provide you with a larger selection. The more pigs you have to choose from, the better your chance of selecting a winner, but do not forget to consider convenience and cost. In many areas of Florida, convenience is a major consideration. It is probably not wise to drive more than three hours for one pig when usable pigs are available locally. Cost is a very important factor in selection. Know feeder pig prices before leaving home. Current prices can be obtained from newspapers, radio and TV farm shows, livestock markets or your local Extension livestock agent. Try to keep your cost similar to industry standards. This means that pigs should be bought for slightly over market price. This will reward the producer for losing his best pigs and the inconvenience of entertaining guests, but will not eliminate your chance of making a profit.

\section{Buying Pigs in Groups}

Long term relationships between youth programs and hog producers can be protected by decreasing the amount of time the producer spends with each exhibitor. Since most producers are very busy and may not allow people to enter their facilities for herd health reasons, the best method of buying pigs is in groups. The best procedure is to send a qualified adult to purchase and haul the desired number of pigs. The exhibitors then draw a number for selection sequence and the exhibitor with number one selects a pig first, number two second, and so on. Most producers are interested in how well their pigs do in the show. A thank-you letter to the producer indicating how his pigs placed will generally be greatly appreciated. Following these procedures will help ensure that quality pigs are available for years to come and that the producer is a committed supporter of the program.

\section{Breed Type}

It is more important to have a good quality pig than a certain breed or color. However, there are certain advantages and disadvantages of each breed that should be considered when selecting a pig. Durocs are usually considered the best performance breed. Pigs of this breed generally have high average daily gains and feed conversion rates. Hampshire and Poland China pigs are considered the heaviest muscled and freest from fat at market weight. Although the white breeds (Yorkshire, Landrace, and Chesterwhite) are less desirable in postweaning traits, they are superior mothers. Therefore, it is common to see the "blue-rumped" or "blue-butted" crossbreds in market hog shows.

\section{The Ideal Market Hog}

Before you can select a pig, you must first know what you are trying to produce. What is the judge looking for? There is no perfect market hog, but there are some ranges within which a champion should fall. An ideal show pig should be between 210 and 260 pounds, have less than one inch of fat over the last rib, and have above average muscle thickness. Therefore, he would be a US\# $1 \mathrm{Hog}$. Pigs vary in frame size, thus creating a wide range of weight among pigs of the same fatness and muscle thickness. The objective is to have a pig at his optimum slaughter weight on the day of the show (Figure 1). 


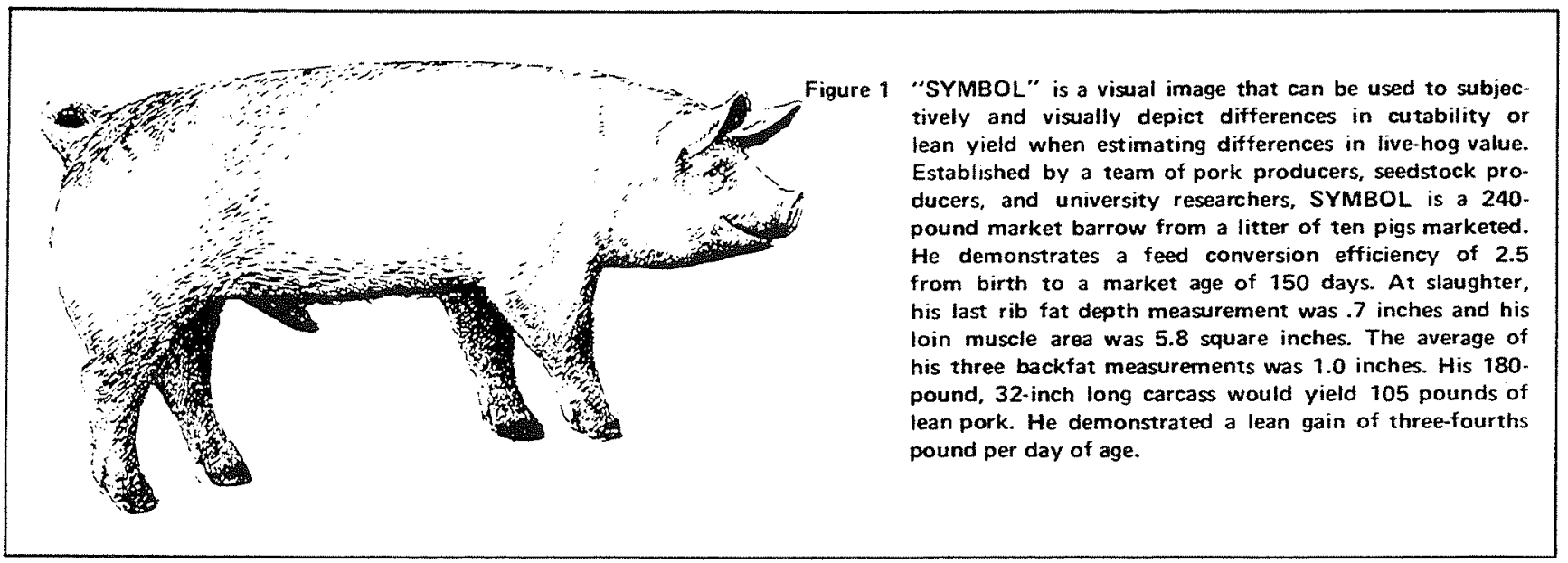

Figure 2

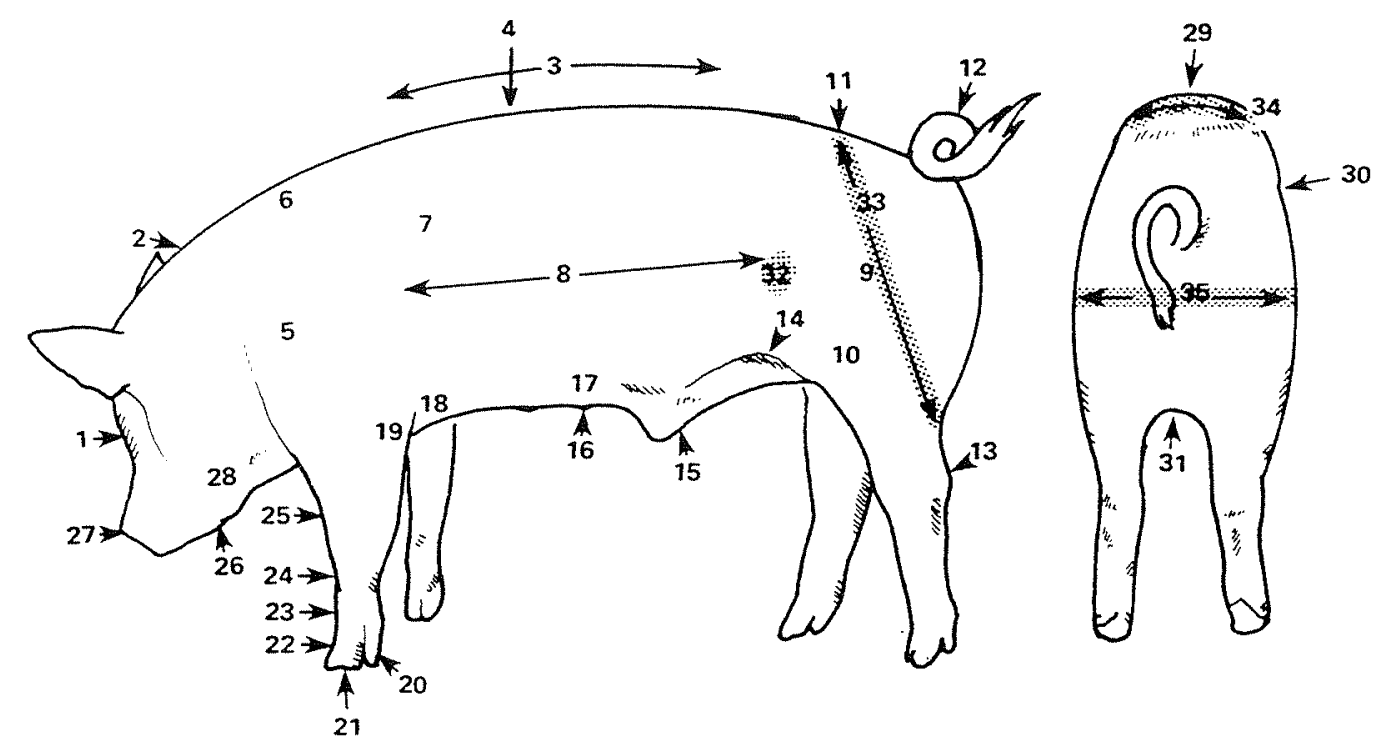

8. Side

9. Ham

10. Stifle

11. Rump

12. Tail

13. Hock

14. Flank

15. Sheath
16. Teat

17. Underline

18. Chest

19. Elbow

20. Dewclaw

21. Foot

22. Pastern

23. Cannon
24. Knee

25. Forearm

26. Jowl

27. Snout

28. Jaw

29. Mid-line Groove

30. Tuck to Loin

31. Twist
32. Stifle

33. Depth of Ham

34. Turn Over Top

35. Width through Stifle

\section{Select a Pig to Fit Your Feeding Program}

In order to discuss feeder pig selection, you must be familiar with the important body part of the pig. These are shown in Figure 2. The skeletal structure of a pig is very important. Pigs must be structurally sound or correct to perform at maximum efficiency in the finishing barn. When selecting pigs, choose those that have adequate slope and cushion in the pastern, shoulder and hock joints.
Avoid straight shouldered or straight legged pigs. The desirable and undesirable structures are shown in Figure 3.

Only pigs with above average muscle thickness should be selected. The muscle indicators most of ten used are the stifle and depth of ham from the side view, and the width through the stifle and turn over the top from a rear view. These areas are highlighted in Figure 2. 


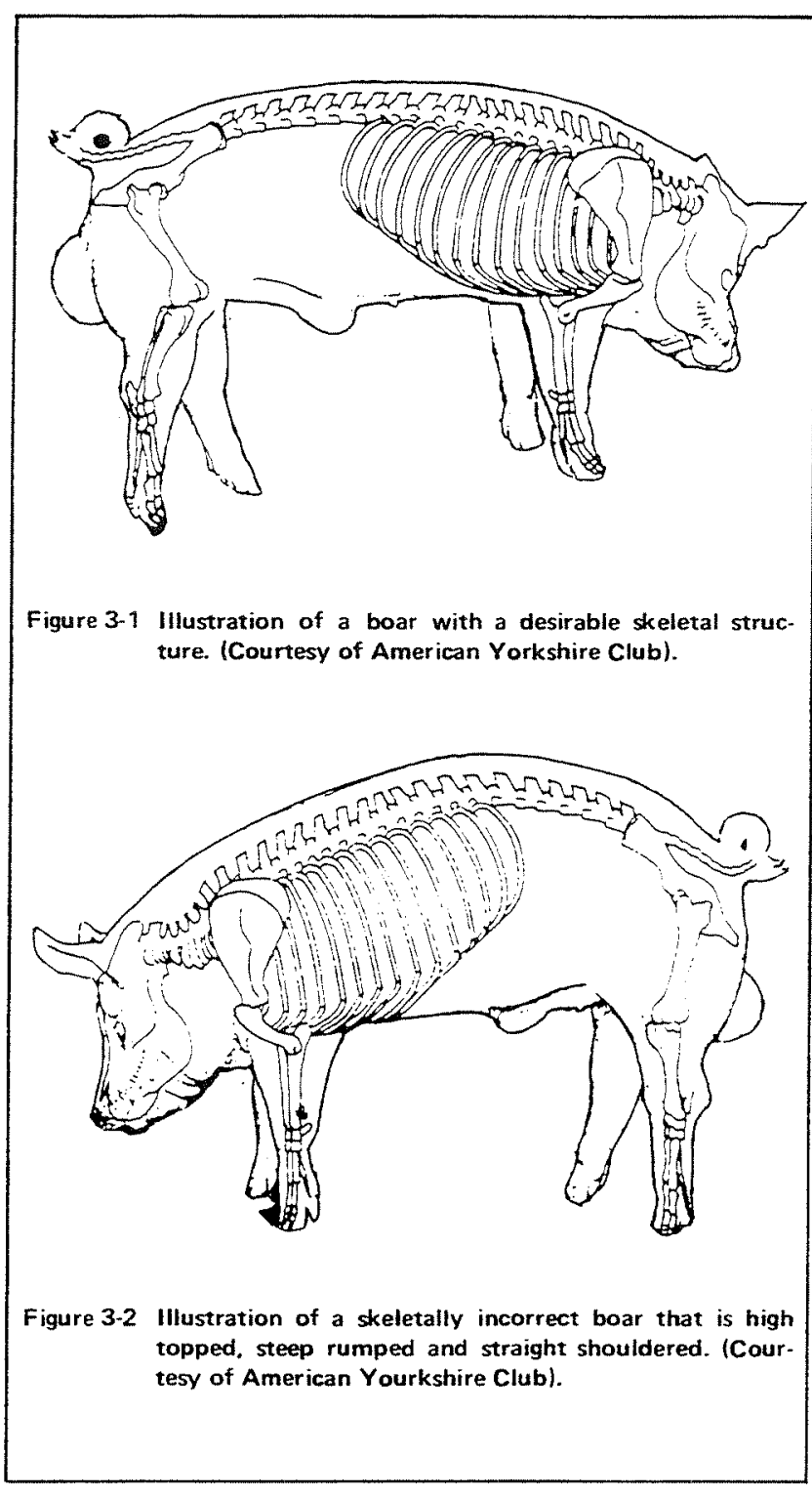

A good feeder pig should be:

1. trim

2. loose but thick in his muscle structure

3. big framed, growthy and stout

4. long and deep in his rib and flank

5 . heavy boned

6. structurally sound

Desirable feeder pig conformation is shown in Figure 4.

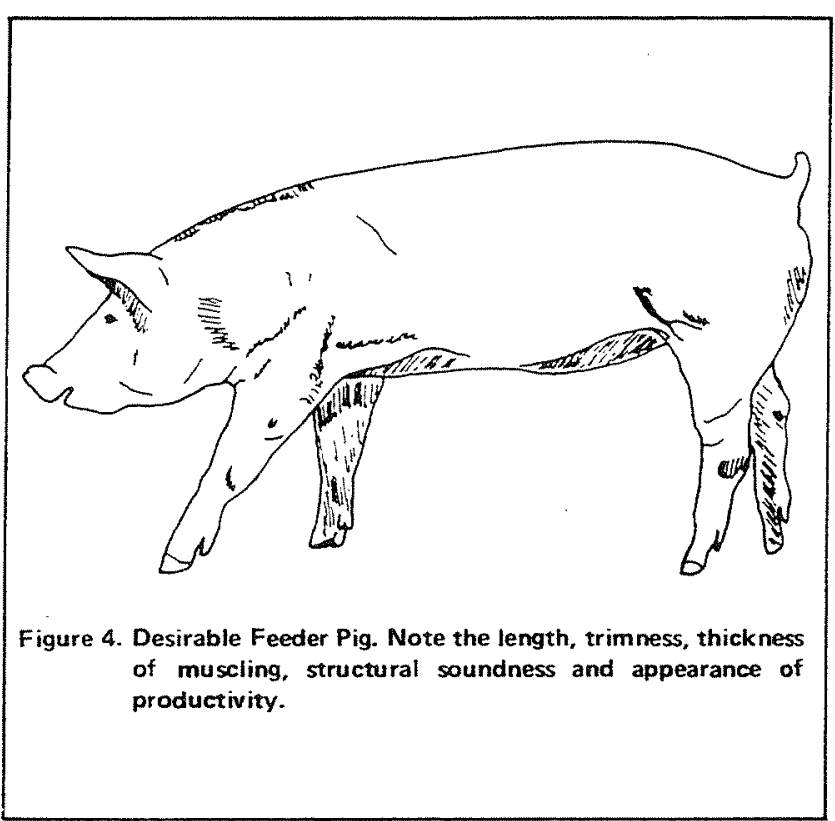

What Weight Pig Should I Buy?

To answer this question you must know:

1. the length of the feeding period

2. the expected daily gain

3. the optimum slaughter weight of the pig

The product of the first two will provide the total pounds gained during the feeding period, which when subtracted from the optimum slaughter weight results in the purchase weight of the pig.

Example: 100 day feeding period

1. 7 pounds average daily gain 230 pounds optimum slaughter weight

$100 \times 1.7=170$ pounds gained during feeding period

$230-170=60$ pound purchase weight

\section{What Daily Gain Should I Expect?}

It is best to use a conservative estimate to guard against sickness, poor quality feed, injuries, or other unplanned problems. Remember, it is easier to slow a pig's rate of gain than to increase it. A good rule of thumb is 1.7 pounds of gain per day for large, rapidly growing pigs. The range you will be working with is 1.4 to 2.0 pounds per day. Figure 5 shows average daily gains for pigs by weight. Check with the producer to find out if related pigs have been finished and their gains recorded. 


\begin{tabular}{cc}
\hline Weight (\#) & ADG|(\#) \\
\hline 40 & 1.2 \\
100 & 1.5 \\
150 & 1.8 \\
200 & 2.0 \\
\hline
\end{tabular}

Figure 5. Approximate Average Daily Gain of Pigs of Different Weights.

\section{How Can I Determine the Optimum Slaughter Weight?}

Again, the best source of information regarding expected performance is provided by related pigs, so ask the producer where your pig is purchased. The next best method of determination is the use of frame size. Pigs vary in their mature skeletal size. Therefore, pigs of different frame size reach their optimum slaughter point at different weights. When a large and small frame pig are compared at a given weight, the small frame pig will be shorter and deeper bodied in relation to its height at the shoulder. The larger the frame size of the pig, the heavier his optimum slaughter weight. Figure 6 shows pigs with optimum slaughter weights of 200 , 230 , and 250 pounds. The USDA Feeder Pig Grades classifies pigs according to frame size and muscle thickness (Figure 7).

\section{Summary}

By buying a healthy, structurally sound US\#1 feeder pig at the correct weight for your feeding period, you should have a successful project in terms of education, profit and personal satisfaction.

\section{Additional Activities}

1. Attend feeder pig selection clinics and workshops. Contact surrounding counties for potential programs.

2. Attend shows in surrounding counties and observe the pigs shown and how they are placed.

3. Participate on your county livestock judging team.

4. Visit area producers and livestock markets.

5. Contact breed associations for information.

6. Study USDA feeder pig grades.
Figure 6

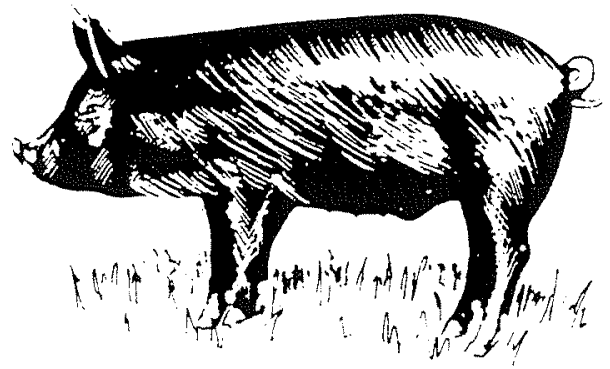

200 pounds

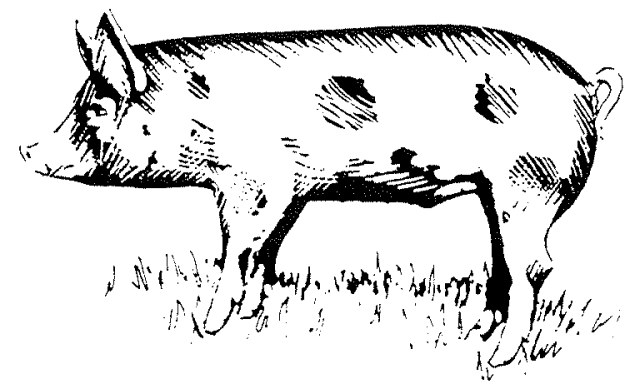

230 pounds

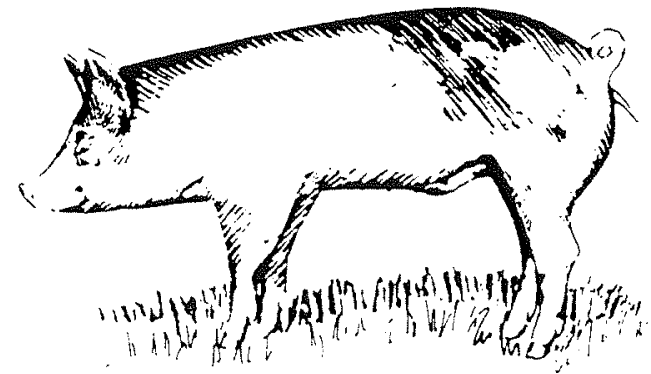

250 pounds 

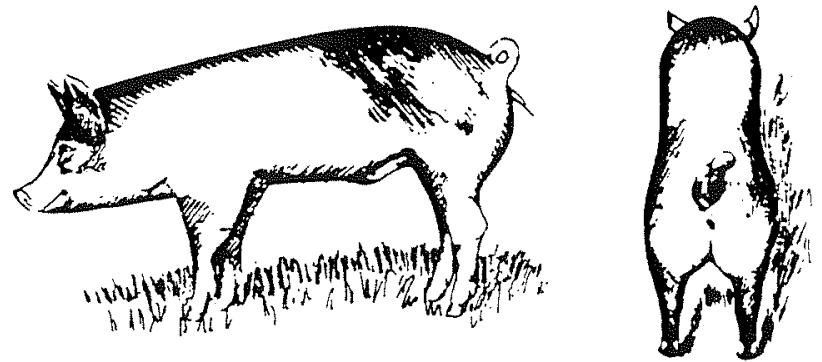

U.S. No. 1

This U.S. No. 1 grade feeder pig has very thick muscling and a large frame which will allow him to reach $220 \mathrm{lbs}$. with a low degree of fatness. Notice from the rear that the legs are set wide apart because of the very thick muscling. Also note that the hams are wider than the loins. From the side he is trim throughout, and he will have a high degree of trimness even at market weight.

Feeder pigs in this grade are expected to produce U.S. No. 1 grade carcasses when slaughtered at $220 \mathrm{lbs}$
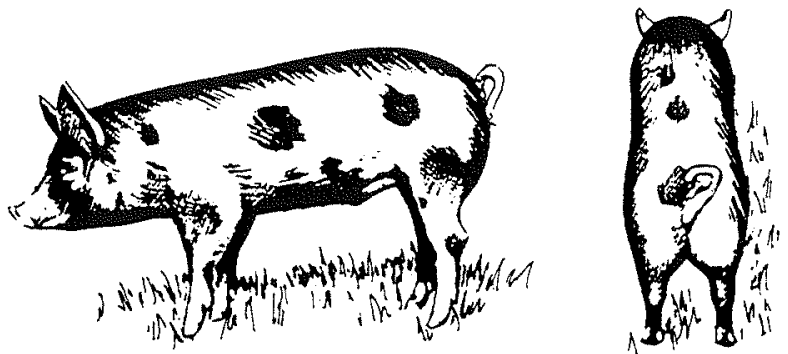

U.S. No. 2

This U.S. No. 2 grade foeder pig has moderately thick muscling and a moderately large frame. He should reach $220 \mathrm{lbs}$. with only a moderate degree of fatness. As viewad from the rear, the hams are slightly wider than the loin. The legs are moderately wide-set indicating moderately thick muscling. From the side he has begun to lose the took of trimness shown by the No, 1 barrow in that the jowl and flank are beginning to fill with fat.

Foeder pigs in this grade are expected to produce U.S. No. 2 grade carcasses when slaughtered at $220 \mathrm{lbs}$.
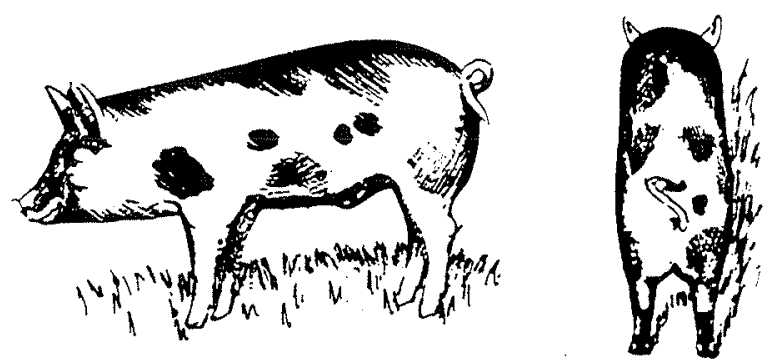

\section{U.S. No. 3}

This U.S. No. 3 grade foeder pig has slightly thin muscling and a slightly small frame. When he reaches $220 \mathrm{lbs}$ he will have a high degree of fatness. From the rear he looks relatively uniform in width through the hams and loin bocause of the low degree of muscling and relatively high degree of fatness. And because of his slightly thin museling, the legs are set fairly close together. When viewed from the side he shows definite signs of fat already being deposited in the jowl and flank.

Feeder pigs in this grade are expected to produce U.S. No. 3 grade carcasses when slaughtered at 220 lbs.

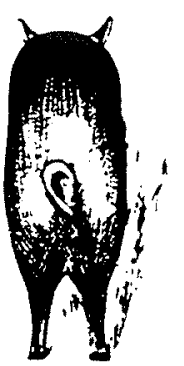

U.S. No. 4

This U.S. No. 4 grade feeder pig has thin muscling and a small frame. At $220 \mathrm{lbs}$, he will have a very high degree of fatness. From the rear he is uniform in width through the hams and loins and the back if rather flat. Also, the logs are set close together because of the thin muscling. Even at this size, from the side he is beginning to look wasty throughout. The jowl and flank are moderately full. Also, the lower parts of the hams are beginning to fill with fat.

Feeder pigs in this grade are expected to produce U.S. No. 4 grade carcasses when slaughtered at $\mathbf{2 2 0} \mathrm{lbs}$

\section{U.S. Utility}

This U.S. Utility grade foeder pig is unthrifly because of disease or poor care. However, his unthrifty condition is not so serious that he could not recover with proper care and treatment. Notice the wrinkled skin, rough unkempt appearance and the head which appears larger than normal. These are typical characteristics of pigs in this grade. If their unthrifty condition is corrected, pigs in this grade may become a No. 1, 2, 3 or 4 at 220 Ibs. Cull feeder pigs, although not shown will be less thrifty and will require a long and costly feeding period to reach market weight.

U.S. Utility grade feeder pigs whose unthrifty condition is not corrected will produce U.S. Utility Grade carcasses. 
1. This document is 4HSWG04 of the Florida 4-H Youth Development Program, Florida Cooperative Extension Service, Institute of Food and Agricultural Sciences, University of Florida. Reviewed June 2002.

2. Marshall, Walker and TenBroeck are Assistant Professors, Animal Science Department, Gainesville. Prichard is Assistant Professor, North Florida Research and Education Center, Quincy, IFAS, University of Florida.

COOPERATIVE EXTENSION SERVICE, UNIVERSITY OF FLORIDA, INSTITUTE OF FOOD AND AGRICULTURAL SCIENCES, Christine Taylor Waddill, Director, in cooperation with the United States Department of Agriculture, publishes this information to further the purpose of the May 8 and June 30, 1914 Acts of Congress; and is authorized to provide research, educational information and other services only to individuals and institutions that function without regard to race, color, age, sex, handicap or national origin. The information in this publication is available in alternate formats. Single copies of extension publications (excluding 4-H and youth publications) are available free to Florida residents from county extension offices. Information on copies for out-of-state purchase is available from Publications Distribution Center, University of Florida, PO Box 110011, Gainesville, FL 32611-0011. 